\title{
Multilinguales
}

$10 \mid 2018$

Langues et médias dans les milieux plurilingues

\section{La gestion interculturelle de la classe de FLE au cycle secondaire en Algérie}

The intercultural management of the secondary cycle of FLE a class in Algeria

\section{Dalila Berkani}

\section{(2) OpenEdition}

\section{Journals}

Édition électronique

URL : http://journals.openedition.org/multilinguales/3776

DOI : $10.4000 /$ multilinguales.3776

ISSN : 2335-1853

Éditeur

Université Abderrahmane Mira - Bejaia

Référence électronique

Dalila Berkani, «La gestion interculturelle de la classe de FLE au cycle secondaire en Algérie »,

Multilinguales [En ligne], 10 | 2018, mis en ligne le 31 décembre 2018, consulté le 21 décembre 2020.

URL : http://journals.openedition.org/multilinguales/3776 ; DOI : https://doi.org/10.4000/

multilinguales.3776

Ce document a été généré automatiquement le 21 décembre 2020.

\section{(c) (1) (9)}

Multilinguales est mise à disposition selon les termes de la Licence Creative Commons Attribution -

Pas d'Utilisation Commerciale - Pas de Modification 4.0 International 


\section{La gestion interculturelle de la classe de FLE au cycle secondaire en Algérie}

The intercultural management of the secondary cycle of FLE a class in Algeria

Dalila Berkani

1 L'avantage de l'apprentissage des langues étrangères n'est plus à démontrer parce qu'il devient actuellement une nécessité à l'ère de la mondialisation et du développement des relations internationales. En prenant en compte de telles données contemporaines, nous proposons, à travers cet article, d'interroger la qualité de la gestion culturelle et interculturelle en classe de FLE en Algérie, précisément au cycle secondaire. La culture cible représente la culture étrangère qui appartient à un peuple, à une nation, à une ethnie ou à une civilisation. Les composantes de la culture feront l'objet d'un questionnaire adressé à des enseignants de FLE au cycle secondaire en Algérie, en raison du constat d'échec interculturel dans plusieurs classes de FLE au cycle secondaire. En effet, l'intervention interculturelle des enseignants de FLE est complètement dépouillée du contenu culturel cible. Pourtant,

la culture dans toute ses formes est de plus en plus incontournable à l'école parce qu'elle est au cœur de la formation, de l'éducation, de l'étique, ce qui lui confère une importance capitale par rapport aux autres disciplines scolaires (Galisson et Puren, 1999 : 96).

2 S'il y a un déficit au niveau de la pédagogie interculturelle en classes de FLE au secondaire, les questions suivantes s'imposent: Comment aider l'enseignant de FLE à développer la compétence interculturelle de ses apprenants en classe de FLE pour favoriser les interactions sociales? Comment prendre en charge l'interculturel en classe de FLE?

3 A travers cette étude, nous essayons de préconiser un enseignement qui ne dissocie le FLE ni de son contenu culturel ni de l'interculturel que sa présence provoque. De ce fait, décrire les ruptures qui existent entre les ambitions institutionnelles et didactiques de natures culturelles et interculturelles et l'encadrement culturel et interculturel en 
classe de FLE au secondaire en Algérie permettra de proposer un modèle de gestion interculturelle à la lumière des recherches en didactique des langues-cultures (Puren, 2011 et 2013) et ceux de l'interculturel (De Carlo, 1998 et Puren, 2008). Dans cette optique, nous nous référons au CECRL (2001) ainsi qu'aux écrits sur la culture (Porcher, 1996) et sur l'éducation interculturelle (Martineau, 2005).

\section{Culture et interculturel}

Notre étude est basée sur une enquête menée auprès d'enseignants de FLE. A travers les données de cette enquête, nous allons faire une proposition pour une gestion interculturelle de la classe de FLE d'où la nécessité, à travers un soubassement théorique, de définir le concept de culture.

La culture

5 Tylor $(1873: 1)$ affirme que

La culture désigne (...) est cet ensemble complexe qui comprend les connaissances, les croyances, l'art, le droit, la morale, les coutumes et toutes les autres aptitudes qu'acquiert l'homme en tant que membre d'une société.

6 Selon cet anthropologue la définition de la culture se résume en la manière de penser, d'agir et de sentir par un groupe de personnes. Elle est considérée comme un être vivant qui influence le comportement de l'autre. Dans ce sens, Porcher (cité par Cuq et Gruca, 2002 : 83) explique que

La culture est un ensemble de pratiques communes, de manières de voir, de penser et de faire qui contribuent à définir les appartenances des individus, c'est-à-dire des héritages partagés dont ceux- ci sont les produits et constituent une partie de leur identité.

7 Après ces définitions, la notion a évolué et le trajet sémantique qu'a connu le concept de culture nécessite de s'arrêter sur une définition plus récente proposée par De Carlo (1998 : 34) qui souligne que

La culture dans son sens ethnographique est cet ensemble complexe qui comprend la connaissance, les croyances, l'art, la morale, le droit, les mœurs et toute capacité et habitude acquises par l'homme comme membre d'une société.

8 En didactique des langues étrangères, la culture est définie comme la capacité de faire des différences, c'est-à-dire de construire et de légitimer des distinctions (distinguer, c'est être capable de ne pas confondre), ce qui signifie qu'il faudrait toujours évoquer la culture au pluriel parce qu'il n'y a pas de culture pure.

La culture d'une société réunit religion, histoire, civilisation, science, art et littérature. Cette dernière est le moyen idoine, en classe de langues, pour connaître l'autre. Les systèmes scolaires placent l'enseignement de la littérature au centre des objectifs visés.

La culture se compose de trois éléments différents. Chacun de ces éléments fait partie d'un niveau de culture particulier :

-Les objets matériels (vêtements, gastronomie, etc.) font partie du niveau culturel superficiel ;

-Les techniques et pratiques (rituel, normes, pratique économique, écologique, etc.) font partie du niveau culturel moyen ;

-Les données mentales (la façon de penser, de réfléchir, d'agir, les valeurs, les principes, les croyances, etc.) font partie du niveau culturel profond qui constitue le noyau dur de la culture. 


\subsection{Définition de l'interculturel}

11 La notion d'« interculturel » est très liée aux changements politiques, économiques et sociaux.

L'intégration du concept d'interculturel en didactique des langues étrangères est indispensable, parce que les classes de langue sont un lieu de rencontre et de contact des diverses cultures. Par conséquent, un métissage culturel règne et unit les partenaires de la classe de langue. Selon Jean-Pierre ( $2003: 136-137)$ :

L'interculturalisme affirmait que l'important était le préfixe inter-, qui permettait de dépasser le multiculturel. L'interculturel, en effet, suppose l'échange entre les différentes cultures, l'articulation, les connexions, les enrichissements mutuels. Loin d'être un appauvrissement, comme les conservateurs l'affirmaient, le contact effectif de cultures différentes constitue un apport où chacun trouve un supplément à sa propre culture (à laquelle il ne s'agit bien sûr en rien de renoncer).

La pédagogie interculturelle prend en charge l'apprenant dans la mesure où elle lui fournit une formation spécifique à la prise de conscience du rôle de la culture dans la rencontre et l'échange avec l'autre. Donc, l'apprenant est impliqué dans le processus de ses apprentissages. L'école est censée former l'élève à s'ouvrir sur les autres cultures par le biais de l'interculturel qui est :

La capacité à gérer les phénomènes de contact entre cultures différentes lorsque l'on communique avec des étrangers dans le cadre de rencontres ponctuelles, d'échanges, de voyages ou de séjours touristiques, en particulier en repérant les incompréhensions causées par ses représentations préalables de la culture de l'autre, et les mécompréhensions causées par les interprétations faites sur la base de son propre référentiel culturel (Puren, 2013 : 05).

La compétence interculturelle est considérée comme une série d'interactions, d'échanges, de partages et de réciprocités entre les individus socio-culturellement différents, comme le précise Demorgon (1989 : 225) :

Le préfixe inter qui suggère des interactions, des échanges, des partages, des complémentarités, des coopérations, des réciprocités,[...], sert à entretenir, dans le meilleur des cas, des souhaits, des espoirs, un idéal à atteindre: celui d'une coexistence pacifique et solidaire entre les populations.

L'acquisition des compétences interculturelles conduit l'apprenant à avoir un ensemble de connaissances sur la culture de l'autre, des connaissances relatives aux croyances, aux civilisations et aux traditions d'une société étrangère. En effet, les chocs culturels et les préjugés seront évités et par conséquent, l'apprenant sera apte à interagir dans les diverses situations de communication en général, et celles du français langueculture étrangère, en particulier.

\section{Choix méthodologique}

15 L'enquête réalisée dans le cadre de cette étude a été menée auprès d'enseignants du cycle secondaire, en avril 2017. Elle relève d'une recherche en cours au niveau de deux wilayas du nord-ouest de l'Algérie (Tlemcen et Aïn- Témouchent).

16 Le questionnaire remis à vingt enseignants a pour objectif de vérifier s'ils sont formés à la gestion interculturelle en classe de FLE au secondaire. Le questionnaire est axé, dans 
un premier temps, sur la notion de compétence et de ce qu'elle représente pour les enseignants.

Dans un second temps, les questions sont orientées plutôt vers la formation des enseignants à la notion de culture, à ses manifestations en classe de FLE, ainsi qu'à la prise en considération de la compétence culturelle. Les dernières questions sont réservées à l'interculturel, au degré de prise en compte de cette compétence ainsi qu'à son installation.

\section{Présentation des données recueillies}

Les vingt enseignants ayant accepté de répondre au questionnaire sont diplômés en langue française. Ils exercent dans dix lycées différents des wilayas d'Aïn-Témouchent et Tlemcen. Parmi ces enseignants, cinq sont recrutés depuis deux ans et huit enseignants depuis plus de dix ans. Sept enseignants exercent depuis plus de dix-sept ans.

Pour sept enseignants, les principales compétences visées par l'enseignement des langues en général sont les compétences communicatives; pour cinq autres, c'est parler et écrire et pour les huit enseignants restants, c'est comprendre, parler et écrire.

Pour six enseignants, les éléments qui composent ces compétences sont les éléments linguistiques; pour cinq enseignants, ce sont plutôt les éléments linguistiques et sémantiques; pour cinq autres, les principales compétences visées sont de nature à la fois linguistique et culturelle, alors que quatre enseignants pensent qu'elles sont de nature verbale et paraverbale.

21 Après avoir collecté des informations sur la (les) définition (s) que les enseignants attribuent à la notion de compétence, nous avons orienté les questions vers le concept de culture. Les enseignants interrogés ont donné les définitions suivantes :

- Les traditions et les mœurs (trois enseignants);

- Les coutumes, les habitudes et le mode de vie (cinq enseignants);

- L'art, la littérature et la science (cinq enseignants);

- La littérature, les traditions et la manière de communiquer (sept enseignants).

Dans le même ordre d'idées, tous les enseignants enquêtés affirment qu'il y a différents types de cultures. Cependant, ces types de cultures ne sont pas les mêmes pour tous les enseignants. Pour cinq enseignants, les types de cultures sont les coutumes, les habitudes et le mode de vie, alors que pour cinq autres, il s'agit de l'art, de la littérature et de la science. Six enseignants pensent que la culture est soit étrangère, soit locale. Par ailleurs, deux enseignants estiment qu'il existe plusieurs types de cultures telles que la culture de la paix, la culture de la lecture, la culture de la communication, etc., et deux autres pensent que la culture est soit ancienne (culture de nos ancêtres) soit nouvelle (notre culture contemporaine).

Cependant, seuls six enseignants enquêtés enseignent la culture française dans leurs classes de FLE. Sur ces six enseignants, un seul l'enseigne sur la base de textes littéraires et autres théâtraux à lire et à comprendre; trois enseignants sur d'autres supports pédagogiques à comprendre tels que les chansons, les documents audiovisuels, les images, etc. Enfin, deux enseignants affirment qu'ils proposent d'abord aux apprenants des textes théâtraux à lire et à comprendre, avant de leur demander de produire et de jouer des saynètes. 

pour quatre enseignants, un savoir et un savoir-faire mobilisés dans les différentes situations de communication. Par contre, neuf enseignants n'ont pas exprimé ce que représente pour eux la compétence culturelle.

confusion dans la définition de la notion de compétence culturelle est justifiée par le fait que tous les enseignants ont été formés, à l'université, à la culture française et non pas à l'installation des compétences culturelles françaises chez les apprenants de FLE. Elle est justifiée aussi par la complexité du concept de culture lui- même.

Un véritable complexe. Ceux qui s'y expriment ne la comprennent pas forcément mieux que ceux qui y sont étrangers. Une compréhension supérieure ne peut être obtenue qu'à travers un laborieux travail non seulement d'ordre communicatif mais surtout coopératif et même compétitif, reposant sur l'effectivité des interactions avec autrui en l'accompagnant de la possibilité de contestations mutuelles (Demorgon, cité par Puren, $2011: 19$ ).

Sept enseignants pensent que la formation des enseignants de langues étrangères à l'installation de compétences en culture française est très importante. Ils pensent aussi qu'elle a un impact sur le niveau de l'apprenant. Cinq enseignants affirment qu'elle est nécessaire pour exercer les apprenants de FLE aux pratiques culturelles dans diverses situations de communication, au moment où six autres trouvent qu'elle est essentielle, surtout si elle s'effectue à l'étranger. En effet, toute langue est indissociable de sa culture. Par contre, deux enseignants supposent qu'elle n'est pas indispensable. Donc, les enseignants sont conscients qu'ils ont besoin de connaissances approfondies dans ce sens, afin d'assurer un encadrement culturel de qualité.

Céponses ont préparé des questions étroitement liées à la notion de culture et à la compétence culturelle. D'ailleurs, pour ce qui est de l'interculturel, un enseignant pense qu'il représente l'émancipation, un autre pense qu'il s'agit de l'épanouissement, alors que trois autres estiment qu'il s'agit plutôt de l'enrichissement culturel. Le fait d'avoir plusieurs cultures est synonyme d'interculturel pour huit enseignants, alors que pour sept autres, c'est le contact avec une autre culture qui engendre l'interculturel.

La compétence interculturelle représente la connaissance de l'autre, selon trois enseignants, et pour quatre enseignants, c'est connaître sa culture et les cultures des autres: leurs pays, leurs littératures, leurs modes de vie, leurs cuisines, etc. Un enseignant pense qu'il s'agit de l'universalité et du fait d'être tolérant, tandis qu'un autre enseignant pense qu'il s'agit tout simplement d'être épanoui. Cinq enseignants pensent qu'acquérir une compétence interculturelle, c'est avoir l'aptitude à communiquer dans une langue avec l'autre, tout en interprétant et comprenant ses comportements et son langage non verbal. Pour six enseignants, il s'agit de la maitrise de l'alternance de deux cultures ou plus.

Pour gérer les différences culturelles liées aux générations dans la relation enseignantapprenant, treize enseignants utilisent des outils didactiques qui correspondent à l'âge et à la génération des apprenants, trois enseignants tentent de comprendre comment les jeunes apprenants réfléchissent pour pouvoir agir en classe de FLE et quatre enseignants essaient de découvrir les centres d'intérêts des apprenants pour pouvoir les exploiter en classe de FLE.

30 Ce genre de gestion nécessite des outils didactiques. Dans ce sens, pour gérer les différences culturelles liées à l'écart culturel entre l'apprenant-lecteur et le texte en culture et français langue étrangères :

Multilinguales, 10 | 2018 
deux enseignants affirment qu'ils utilisent l'illustration en images ;

trois enseignants optent pour l'explication des mots difficiles ;

six enseignants exploitent le contexte culturel du texte ;

neuf enseignants préfèrent l'explication des mots difficiles et l'illustration en images et en documents audiovisuels.

Ce genre de gestion nécessite aussi une formation préalable des enseignants. Trois enseignants déclarent avoir été formés à l'interculturel et non pas à l'installation des compétences interculturelles et ce, à l'université. Toutefois, dix-sept enseignants n'ont jamais bénéficié de formation dans ce sens. Par conséquent, aucun enseignant enquêté n'évalue les compétences culturelles et interculturelles de ses élèves.

La plupart des enseignants questionnés signalent qu'ils n'ont jamais été formés ni à l'installation ni au développement des compétences culturelles cibles et celles interculturelles, pourtant ils ont besoin d'être formés dans ce domaine. Peu d'enseignants déclarent avoir bénéficié de ce genre de formation, ce qui a un impact néfaste sur la qualité de l'enseignement et celle de l'apprentissage.

Dans cette optique, dix enseignants pensent qu'une telle formation est très importante parce qu'elle influe sur le niveau de l'apprenant. Ces mêmes enseignants insistent sur la nécessité d'une formation-recyclage en didactique du FLE, particulièrement en interculturel. Quatre enseignants trouvent que ce genre de formation est nécessaire pour exercer les apprenants de FLE aux pratiques culturelles dans diverses situations de communication. Six enseignants qualifient cette formation d'essentielle, surtout si elle s'effectue à l'étranger, puisque toute langue est indissociable de sa culture. Ces mêmes enseignants insistent sur la nécessité d'une formation- recyclage en didactique du FLE.

\section{Analyse interprétative des résultats}

Durant la collecte des réponses, nous avons constaté que la majorité des enseignants n'ont pas une représentation pertinente sur les concepts clés de la gestion interculturelle en classe de FLE. Les enseignants enquêtés manquent d'idées claires sur les compétences culturelle et interculturelle, alors que les concepts d'interculturel et de compétence interculturelle sont visés par les documents officiels. Selon le bulletin officiel de l'éducation nationale (2008: 13), « la maitrise des langues étrangères de grande diffusion est indispensable, pour participer effectivement et efficacement aux échanges interculturels $»$.

La majorité des enseignants enquêtés pensent qu'ils ont besoin d'être formés à l'installation et au développement des compétences culturelles en français et des compétences interculturelles pour pouvoir gérer «interculturellement» la classe de FLE, puisqu'ils n'ont jamais bénéficié d'une formation dans ce domaine. Ils pensent que ce genre de formation se répercute positivement sur la qualité de l'enseignement/ apprentissage de la langue-culture française et sur la gestion interculturelle en classe de FLE. Nous notons que seuls trois enseignants du public enquêté ont bénéficié d'une formation interculturelle à l'université. En outre, la majorité des enseignants ne prend pas en considération l'aspect culturel du français dans l'enseignement du FLE. Si l'enseignant ne prend pas en considération la culture, il enseigne un idiome et non pas une langue. Les supports pédagogiques, étant la manifestation des faits culturels réels 
de l'étranger, contribuerait énormément à la compréhension de l'élément culturel cible de la langue cible. Toutefois, quand l'enseignant n'est pas formé à l'utilisation des supports pédagogiques dans l'encadrement culturel et interculturel des apprenants, ce genre de documents demeure sans efficacité pédagogique. L'accès à la compréhension de l'information culturelle cible de la langue cible pourrait favoriser l'acquisition et le développement d'une compétence interculturelle indispensable à l'apprentissage des aspects linguistique et culturel du FLE et au développement des compétences communicatives dans la même langue- culture. Dans cette optique, les auteurs du Cadre européen commun de référence pour les langues (Conseil de l'Europe, 2001: 84) précisent que :

36 Les aptitudes et savoir-faire interculturels comprennent :

- la capacité d'établir une relation entre la culture d'origine et la culture étrangère

- la sensibilisation à la notion de culture et la capacité de reconnaître et d'utiliser des stratégies variées pour établir le contact avec des gens d'une autre culture

- la capacité de jouer le rôle d'intermédiaire culturel entre sa propre culture et la culture étrangère et de gérer efficacement des situations de malentendus et de conflits culturels

- la capacité à aller au- delà de relations superficielles stéréotypées.

Enfin, tous les enseignants affirment qu'ils n'évaluent pas les compétences culturelles et interculturelles des élèves.

\section{5. État des lieux et proposition pour une gestion interculturelle en classe de FLE en Algérie}

38 A la lumière des données présentées jusqu'à présent, un défi didactique et pédagogique s'impose: les chercheurs en didactique doivent prendre en considération la réalité culturelle propre à l'apprenant algérien en associant la multiculturalité qui caractérise le paysage culturel algérien à la complexité de la nature de l'apprenant en général qui est à la fois cognitif, psychique, social, affectif, linguistique et culturel. Ce projet peut être entrepris grâce à plusieurs facteurs.

\subsection{La formation des enseignants à la sociologie de l'école algérienne : vers une carte sociodidactique et socioculturelle pour l'enseignement du FLE en Algérie}

En Algérie, le statut du français pose un problème de définition et d'action sur le plan didactique, puisque la même langue constitue l'outil d'enseignement en classe de FLE. De plus, cette même langue participe au paysage linguistique métissé de l'Algérie. Réussir la transposition didactique lors de l'encadrement culturel et interculturel dépend de trois conditions distinctes.

La première condition est relative aux pratiques de classe telle que l'interculturel qui doit être fondée sur les données sociolinguistiques et socioculturelles des apprenants algériens, ce qui se répercute positivement sur la qualité de la transposition didactique que l'enseignant doit réaliser constamment pour assurer la médiation entre le savoir, le savoir-faire et le savoir- être culturels et interculturels et l'apprenant. 
41 La deuxième condition est liée à l'urgence de concevoir une didactique spécifique au contexte scolaire algérien. La discipline de didactique du FLE elle-même emprunte aux théories conçues pour la didactique de la langue seconde et celle de la langue maternelle dont la langue cible n'est pas souvent le français, ce qui légitime la négligence de l'aspect sociolinguistique et socioculturel de l'apprenant algérien empêche la redéfinition du statut du français qui ne se fait que grâce à une sociodidactique algérienne.

Le troisième facteur concerne la réconciliation de la sociolinguistique et de la pédagogie algériennes pour permettre aux recherches engagées en didactique des langues et en sociolinguistique d'accéder au rang de recherche-action praxéologiques sous l'égide d'une sociodidactique propre au contexte scolaire algérien.

\subsection{Le développement de la conscience de la ressemblance et de la différence chez l'apprenant dès l'enfance}

Chaque individu a sa propre culture métissée, individuelle, générationnelle, etc. Il est important d'insister, dans un premier temps, sur la ressemblance et la différence des élèves entre eux pour pouvoir, par la suite, faire découvrir à l'élève sa ressemblance et sa différence avec l'autre qui existe dans d'autres sociétés et cultures (altérité), tout en prenant en charge l'apprenant psycho-sociologiquement et tout en lui expliquant que la différence est à l'origine de la ressemblance des individus.

44 A ce stade, il est important de souligner qu'il n'y a pas de culture pure parce que la culture de chaque individu est métissée synchroniquement et diachroniquement.

\section{- Le métissage culturel :}

Si l'assimilation culturelle est un phénomène social qui signifie le processus de l'intégration d'un individu dans une autre société pour acquérir, malgré lui, la culture et le comportement d'autrui, ce qui constitue un changement radical que l'individu doit admettre sans hésitation, le métissage est aussi une découverte de nouvelles cultures, mais sans que l'individu change son identité qui est propre à lui comme son histoire, sa confession, sa langue, etc. Cette découverte permet d'intégrer des éléments culturels nouveaux qui enrichissent sa propre culture individuelle. Le métissage a un grand avantage qui trouve son point fort dans l'identité et l'âme pure de l'écrivain. Celui-ci écrit dans une langue étrangère, mais il s'exprime dans sa culture maternelle. Selon Porcher (cité par Cuq et Gruca, 2002 : 09), « toute culture qu'elle soit sociale, individuelle ou groupale, se définit comme une culture métissée. La notion de culture pure n'a pas vraiment de sens. Ce que nous apprenons modifie notre capital culturel ».

Dans plusieurs pays ou régions, les mises en relation suite à des conquêtes ou des échanges multiples ont permis la fécondité de la création qui a été le reflet de l'interculturel qui en a découlé.

47 Lors de l'encadrement culturel et interculturel, il faut toujours aborder le concept de cultures au pluriel, car il n'existe pas de culture pure. De plus, il est nécessaire d'éviter l'enfermement afin de connaître mieux les gens qui vivent sur la surface de cette planète, il faut les accepter, les tolérer, les aider, les guider et leur parler tels qu'ils sont. 


\section{d'un individu à chaque degré de filiation.} tension et l'opposition qui existent entre deux générations qui ne partagent ni la même époque ni le même âge et se trouvent dans la même situation (Ex : des jeunes et des vieux, des enseignants âgés et des jeunes apprenants, les parents et leurs enfants ...). La 
rencontre de plusieurs générations entraîne le contact de plusieurs cultures appartenant à des générations différentes. Dans cette optique, nous savons avec Donnat et Lévy (2007 : 02) que :

L'approche générationnelle est un type d'analyse originale qui enrichit et dépasse l'analyse par l'âge. Elle s'appuie sur trois principes essentiels :

- ce qui unit lesmembres d'une génération, c'est de vivre la même histoire au même moment de sa vie[...];

- chaque génération est "marquée " - souvent pour la vie - par ses expériences initiatrices vécues au temps de sa jeunesse (c'est la notion de «marqueur générationnel »). [...];

- chaque génération reçoit en héritage les valeurs transmises par celles qui l'ont devancée, mais au sein des générations les plus récentes, on vit et on apprend désormais davantage avec ses pairs qu'avec ses pères (notion de "mimétisme générationnel »).

Parmi les caractéristiques de la génération actuelle nous citons :

- Une génération fondée sur la technologie. On remarque la présence des moyens technologiques dans l'enseignement des langues (enseignement assisté par ordinateur, l'e- learning, le traitement automatique du langage naturel, etc.).

- Une mutation culturelle et sociale caractérise la vie des individus. Dans le domaine de l'enseignement-apprentissage, les anciennes stratégies pédagogiques ne sont pas aussi rentables dans la prise en charge des apprenants du XIème siècle.

- Dans une classe de FLE, on peut remarquer l'existence d'une distance générationnelle entre l'enseignant et l'apprenant ou entre les apprenants.

- Le mode de socialisation des enfants a aussi été modifié. Auparavant, il n'y avait pas d'écoles préscolaires, mais aujourd'hui, il existe divers organismes qui s'occupent de la socialisation des enfants.

\subsection{L'apprentissage de la rencontre et de la communication avec l'autre grâce aux supports pédagogiques appropriés}

Un tel apprentissage se réalise par le biais de la compréhension de documents audio et/ ou audiovisuels authentiques de communications interculturelles et de textes à lire riches d'éléments culturels étrangers.

Par l'intermédiaire de l'enseignement des textes littéraires par exemple, le rôle de l'instruction et celui de l'éducation scolaire sont décisifs puisque l'enseignant tente de fournir une formation linguistique et culturelle sur la langue enseignée. La didactique des langues a besoin de la littérature, mais pour compléter cette équation pédagogiquement, il faut qu'il y ait une formation au niveau des matières enseignées, notamment celles qui ont un rapport avec la culture cible et l'interculturel qui en découle en classe de FLE, par exemple.

En didactique des langues étrangères, la civilisation, la culture et le texte littéraire sont en relation permanente. La pédagogie du FLE se sert des outils didactiques comme le texte littéraire pour faire apprendre aux apprenants le fonctionnement de la langue, la culture et la civilisation étrangères. 


\subsection{Motiver l'apprenant et susciter sa curiosité de découvrir la culture française et d'apprendre le processus interculturel}

A ce stade, il est question de développer chez l'apprenant la compétence de gestion du contact de cultures (culture individuelle, culture française) pour ne pas perdre la compétence de sa culture individuelle et ce, par le biais de la motivation. Selon le dictionnaire de didactique du français langue étrangère et seconde (Cuq, 2003 : 171),

La motivation doit être reconnue et entretenue à court terme: dans tout apprentissage, et dans celui des langues en particulier, la perception que l'apprenant a de soi et celle qu'il se fait de la situation d'apprentissage sont des facteurs importants. Aussi, les renforcements positifs et les appréciations consolidant la confiance et la réussite joueront-ils le rôle de stimulants dans le processus d'acquisition (...).

61 Former l'apprenant à la gestion du contact de cultures permet d'éviter "les chocs culturels" tels que les conflits et malentendus culturels, la déculturation, etc. Cet encadrement doit être de nature interculturelle mais aussi psycho- sociologique afin que l'apprenant tire profit de la communication interculturelle et soit motivé à participer à son acte d'apprentissage en se préparant à être acteur social. D'ailleurs,

La motivation en contexte scolaire est un état dynamique qui a ses origines dans la perception qu'un élève a de lui-même et de son environnement et qui l'incite à choisir une activité, à s y engager et à persévérer dans son accomplissement afin d'atteindre un but » (Viau, 1994 : 13).

62 A ce stade, il faut:

- Apprendre aux élèves le fonctionnement de l'interaction interculturelle, par conséquent on installe l'altérité.

- Expliquer aux élèves les identités sociales : la famille, la religion, la patrie, etc.

- Montrer aux élèves ce qu'ils doivent connaître sur eux-mêmes et sur l'autre. Cela leur permet d'éviter les préjugés et les critiques.

- Apprendre aux élèves l'art de communiquer : bien écouter l'autre avant de réagir.

Les deux schémas suivants résument notre proposition de remédiation à l'encadrement culturel et interculturel en classe de FLE du cycle secondaire en Algérie. 
Schéma 1 : L'interculturel en classe de langues

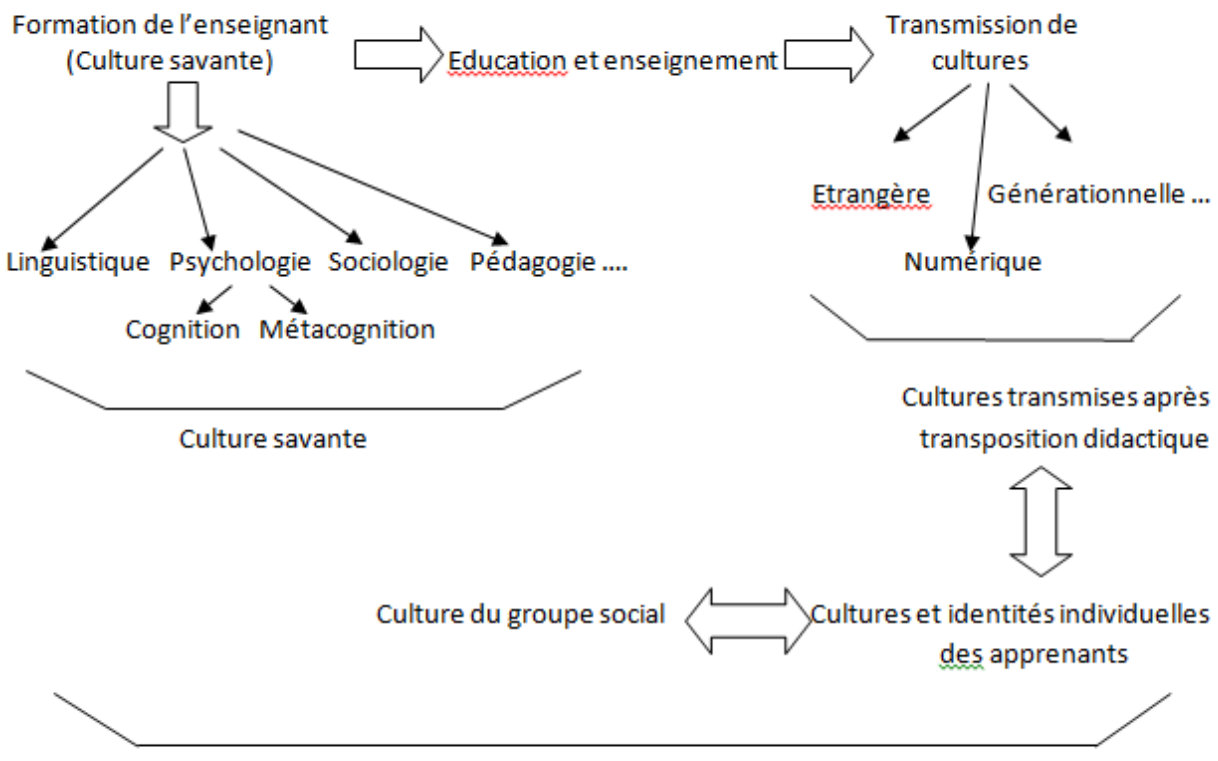

Le processus interculturelen classe de langues

Schéma 2 : L'interculturel en classe de FLCE

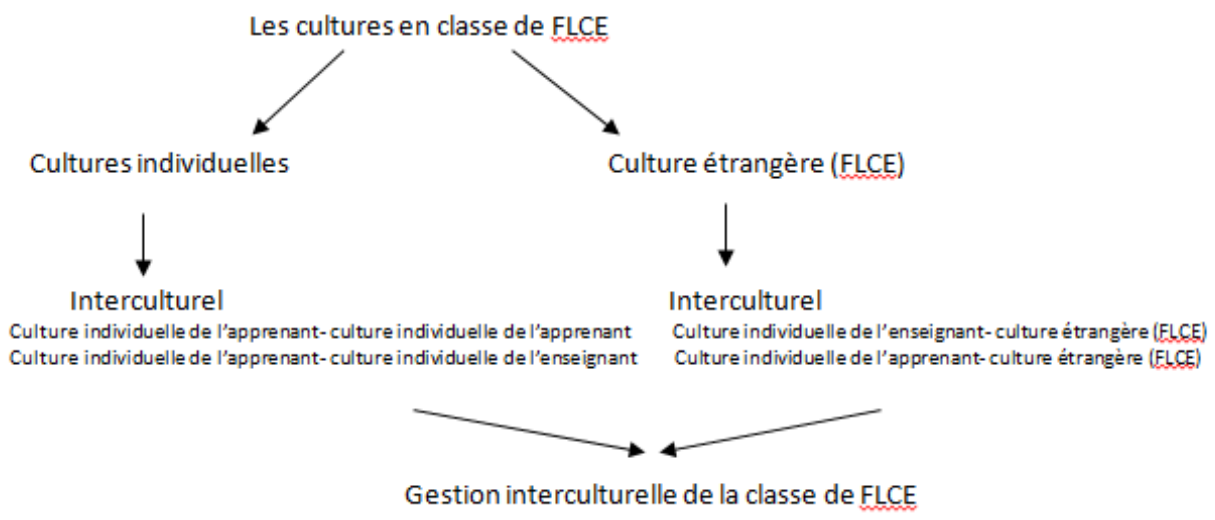

64 L'actualité de l'enseignement des langues en Algérie est focalisée autour des performances du système éducatif, particulièrement en matière d'enseignementapprentissage des langues en général et celui du FLE en particulier dont l'objectif majeur est de former un apprenant capable de communiquer en FLE à l'oral et à l'écrit. Ces ambitions institutionnelles coïncident avec l'avènement de nouveaux modes de communication, suite au développement des techniques de transmission assurant rapidité et large diffusion de l'information. Le rapport à l'autre a énormément changé, d'où la nécessité de la prise en charge de l'aspect culturel et interculturel de (s) langue (s). Notre contribution est centrée sur la place accordée, en classe de FLE, à la culture française cible et à l'interculturel dans les pratiques enseignantes au cycle secondaire au niveau des wilayas de Tlemcen et d'Aïn- Témouchent. Pour cela, nous avons formulé la question suivante: Existe-t-il une intégration de l'aspect culturel français et, par conséquent, une prise en charge interculturelle des apprenants dans l'enseignement du FLE au cycle secondaire en Algérie?

Pour apporter des éléments de réponse à cette question, nous avons élaboré un questionnaire destiné aux enseignants afin de vérifier notre hypothèse qui stipule que 
la formation au cycle secondaire n'intègre pas la relation entre l'aspect linguistique et celui culturel du FLE et ne joint pas, en effet, l'installation et le développement de compétences interculturelles à l'acte d'enseigner.

Les résultats de l'enquête ont permis de confirmer cette hypothèse.

L'enseignement-apprentissage de la culture française cible et de l'interculturel est caractérisé par deux contraintes majeures.

La première contrainte est liée à la pratique de l'enseignant qui doit se préoccuper à la fois de compresser des savoirs et d'envisager les méthodes de transmission les plus adaptées à la situation d'enseignement-apprentissage dans le cadre de la transposition didactique.

La deuxième contrainte est liée à la tâche de l'apprenant qui consiste à transformer le savoir reçu en un outil de réflexion permettant d'agir et de réagir dans des situations de communication diversifiées.

Les deux contraintes tiennent d'une part au savoir nouveau transmis dans un terrain pédagogique particulier sur les plans sociolinguistique, psycholinguistique, socioculturelle, psychosociologique et sociodidactique algérienne, d'autre part à la nature complexe de l'apprenant qui est à la fois linguistique, psychique, social, cognitif, affectif et culturel. Parce que cette dernière nature sous-tend toutes les activités de classe, il s'agira à travers notre intervention de mettre le point sur la nécessité de former les formateurs à la culture cible et à l'interculturel. Ceci permet un rapprochement plus net entre le souci de, non seulement, transmettre un savoir compressé, mais aussi d'envisager une démarche adéquate et le souci de permettre à l'apprenant de réaliser la transformation des connaissances déclaratives en outils d'exécution dans les diverses situations communicatives en FLE.

Pour réconforter notre conception, nous savons que parmi les huit commandements du didacticien que cite Roulet Eddy dans « Des didactiques du français à la didactique des langues ", nous sélectionnons qu' :

«- Il faut connaître la réalité et la complexité du terrain pédagogique ;

- Il faut, à partir de là, construire son objet, ses problèmes, et ne plus croire qu'on

les trouve tout faits sur le terrain (...) ».

69 A la lumière de ces données, nous avons tenté de proposer, à la fin de cet article, des suggestions pour gérer culturellement et interculturellement la classe de FLE au cycle secondaire en Algérie.

\section{BIBLIOGRAPHIE}

BULLETIN OFFICIEL DE L'EDUCATION NATIONALE, « Loi d'orientation sur l'éducation nationale, Préambule ", n 8, Février 2008.

CUQ, Jean-Pierre et GRUCA, Isabelle, Cours de didactique du français langue étrangère et seconde, Presses Universitaires de Grenoble, Grenoble, 2002. 
CUQ, Jean-Pierre, Dictionnaire de didactique du français langue étrangère et seconde, Clé international, Paris, 2003.

DE CARLO, Maddalena, L'interculturel, Clé international, Paris, 1998.

DEMORGON, Jacques, L'exploration interculturelle pour une pédagogie internationale, Armand Colin, Paris, 1989.

CONSEIL DE L'EUROPE, Cadre Européen Commun de Référence pour les langues, Didier,Paris, 2001.

DONNAT, Olivier et LÉVY, Florence, « Approche générationnelle des pratiques culturelles et médiatiques ", Dans Culture prospective, $\mathrm{N}^{\circ} 3$, Cairn. Info, p-p. 01- 31, 2007. https:// www.cairn.info/revue-culture-prospective-2007-3-page-1.htm [consulté le 07 février 2019]. GALISSON, Robert et PUREN, Christian, La formation en question, Clé international, Paris, 1999. LEVI-STRAUSS, Claude, Race et Histoire, Gallimard, Paris, 1987.

MARTINEAU, Stéphane, «L'éducation interculturelle : problématique, fondements et principes d'actions ", Dans L'enseignement, profession intellectuelle, Les presses de l'université Laval, Québec, 2005, pp. 207-230.

ROULET, Eddy, « Des didactiques du français à la didactique des langues », Langue française, $\mathrm{n}$ 82,1989 .

TYLOR, Edward Burnett, La civilisation primitive, Tome 2, Ed. Barbier, Ancienne Librairie Schleicher, Alfred Costes, Éditeur,Paris,1873.

PUREN, Christian, « De l'approche communicative à la perspective actionnelle, et de l'interculturel au co-culturel », 2008. www.christianpuren.com/mes-travaux-liste-et-liens/208e/ [consulté le 07 février 2019].

PUREN, Christian, « Modèle complexe de la compétence culturelle (composantes historiques trans-, méta-, inter-, pluri-, co-culturelles) : Exemples de validation et d'application actuelles ", 2011. www.christianpuren.com/mes-travaux-liste-et-liens/2011j/ [consulté le 07 février 2019].

PUREN, Christian, «La compétence culturelle et ses composantes », 2013. https://

lewebpedagogique.com/alterite/files/2015/10/

PUREN_2013c_Compétence_culturelle_composantes.pdf [consulté le 07 février 2019].

VIAU, Roland, La motivation en contexte scolaire, Editions du Renouveau Pédagogique Inc., SaintLaurent, 1994.

\section{RÉSUMÉS}

La didactique et la pédagogie des langues accordent beaucoup d'importance à la prise en compte de la dimension interculturelle en classe de langue. C'est le cas de l'école algérienne à travers la réforme qui vise à développer, entre autres compétences, la compétence interculturelle.

Malgré ces ambitions, nous avons remarqué, suite à une enquête menée auprès d'enseignants de FLE au niveau de deux wilayas situées au nord- ouest de l'Algérie (Aïn-Témouchent et Tlemcen), que la plupart des enseignants n'ont pas d'idées claires sur le concept de compétences culturelles et celui de compétences interculturelles bien qu'ils confirment que le développement des compétences interculturelles est visé par des programmes de classes de FLE. Suite à ces constats, nous nous interrogeons dans cet article sur la manière d'enseigner l'élément culturel français et les aides qui doivent être apportées à l'enseignant de FLE. Nous supposons que ces aides 
permettront d'éviter d'affaiblir l'élément linguistique et de le l'amputer de son contenu culturel qui le complète. Nous admettons qu'elles permettront par conséquent à l'apprenant de communiquer en FLE correctement. Nous nous interrogeons, enfin, sur la manière de prendre en charge l'interculturel dont la naissance est provoquée, entre autres, par la rencontre de la culture locale (culture des apprenants) avec la culture étrangère en classe de FLE, tout en nous référant aux recherches engagées en didactique des langues-cultures.

C'est dans cette perspective que s'inscrit notre étude qui comportera deux parties : mise en évidence des principales incompatibilités et contradictions que nous venons d'évoquer et quelques propositions didactiques pouvant permettre de les atténuer.

Didactics and language pedagogy, give a great deal of importance to the learning of intercultural and intercultural management at school. This is the case of the Algerian school through the reform which aims to develop, among other skills, intercultural competence.

Despite these ambitions, we have noticed, following a survey of teachers of FLE at the level of a wilaya located in the north-west of Algeria (Ain-Northwestern), that most teachers have no clear ideas about the concept of skills Cultural and intercultural competences, although they confirm that the development of intercultural skills is covered by programmes of FLE classes. Following these findings, we wonder in this article on how to teach the French cultural element and the aid that must be made to the teacher of FLE. We assume that such aid will avoid weakening the linguistic element and impoverishing it from its cultural content that complements it. We accept that they will therefore allow the learner to communicate in FLE correctly. Finally, we wonder about how to take care of the intercultural whose birth is caused, among other things, the meeting of the local culture (learners ' culture) with the foreign culture in the FLE class, while referring to the Research in language didactics-cultures.

It is in this perspective that our study will include two parts: highlighting the main incompatibilities and contradictions that we have just mentioned and enumerating some didactic suggestions that could allow them Mitigate.

\section{INDEX}

Keywords : cultures, otherness, intercultural skills, teacher training, FLE class

Mots-clés : cultures-altérité, compétences interculturelles, formation de formateurs, classe de FLE

\section{AUTEUR}

\section{DALILA BERKANI}

Centre universitaire BELHADJ Bouchaib. Aïn- Témouchent, Algérie 